\title{
Susceptibility of some oral microorganisms to chlorhexidine and paramonochlorophenol
}

\section{Susceptibilidade de alguns microrganismos orais frente à clorexidina e ao paramonoclorofenol}

\author{
Crystiane Venditi Gomes do Amorim* \\ Carlos Eduardo Aun** \\ Marcia Pinto Alves Mayer***
}

\begin{abstract}
Since the use of antimicrobial agents is required in endodontic therapies, this study aimed at determining the minimum inhibitory concentrations (MICs) of chlorhexidine digluconate and paramonochlorophenol (PMC) against microorganisms commonly found in endodontic infections. Both agents were tested by agar dilution tests against Pseudomonas aeruginosa, Staphylococcus aureus, Enterococcus faecalis, Escherichia coli, Candida albicans, Prevotella intermedia, Porphyromonas gingivalis, Porphyromonas endodontalis, Prevotella denticola and Prevotella melaninogenica. The MIC of chlorhexidine ranged from 2.67 to $80.00 \mu \mathrm{g} / \mathrm{ml}$, and the MIC of PMC from 46.67 to $213.33 \mu \mathrm{g} / \mathrm{ml}$. The highest MIC value of PMC was detected for $E$. faecalis whereas $E$. coli was the most susceptible microorganism to this agent. The highest MIC values of chlorhexidine were observed for $P$. aeruginosa whereas $E$. coli and $P$. denticola were the most susceptible microorganisms to this agent. Since the MIC values observed are much lower than the concentrations currently used in the endodontic therapy, it is suggested that both agents are effective in reducing the microbiota in the root canal.
\end{abstract}

DESCRIPTORS: Chlorhexidine; Anti-infective agents, local; Root canal, drug effects.

RESUMO: Tendo em vista a necessidade de se utilizarem agentes antimicrobianos durante a terapia endodôntica, o presente estudo tem por objetivo determinar as concentrações inibitórias mínimas (CIMs) de digluconato de clorexidina e de paramonoclorofenol (PMC) frente a cepas de microrganismos freqüentemente isolados dos canais radiculares infectados. Ambos os agentes foram testados por meio de testes de diluição em meio sólido contra Pseudomonas aeruginosa, Staphylococcus aureus, Enterococcus faecalis, Escherichia coli, Candida albicans, Prevotella intermedia, Porphyromonas gingivalis, Porphyromonas endodontalis, Prevotella denticola e Prevotella melaninogenica. As CIMs de clorexidina variaram de 2,67 a 80,00 $\mu \mathrm{g} / \mathrm{ml}$, e as CIMs de PMC variaram de 46,67 a $213,33 \mu \mathrm{g} / \mathrm{ml}$. A maior CIM do paramonoclorofenol foi frente a E. faecalis, entretanto $E$. coli foi o microrganismo mais susceptivel. A maior CIM do digluconato de clorexidina foi frente a P. aeruginosa, entretanto $E$. coli e $P$. denticola foram os microrganismos mais susceptiveis. Como os valores de CIM observados são bem menores do que as concentrações usadas normalmente na terapia endodôntica, sugere-se que ambos os agentes são efetivos na redução microbiana no canal radicular.

DESCRITORES: Clorexidina; Antiinfecciosos locais; Canal radicular, efeitos de drogas.

\section{INTRODUCTION}

Microorganisms and their products are involved in the etiology of pulpal and periapical diseases ${ }^{26}$. A reduction in the number of living bacteria in the infected root canal is achieved by a combination of measures such as mechanical cleaning, irrigation with various antimicrobial agents and use of antibacterial fillings in the canal. Root canal infections frequently lead to apical periodontitis, depending mainly on the interaction between the infective microorganism and the host's defense.

Microorganisms resident in the oral cavity such as facultative anaerobic streptococci can constitute a significant part of the microflora, mainly in the cervical portion of the exposed dental pulp. Strictly anaerobic oral bacteria, belonging mainly to the genus Prevotella and Porphyromonas, but also species of Actinomyces, Peptostreptococcus

\footnotetext{
*MS, Department of Endodontics, School of Dentistry; **PhD, Department of Endodontics, School of Dentistry; ***PhD, Department of Microbiology, Biomedical Sciences Institute - University of São Paulo.
} 
Amorim CVG, Aun CE, Mayer MPA. Susceptibility of some oral microorganisms to chlorhexidine and paramonochlorophenol. Braz Oral Res 2004;18(3):242-6.

and Fusobacterium nucleatum are prevalent in endodontic infections, and may be the causative agents of periapical lesions ${ }^{9,26,27}$. Other species, such as Pseudomonas aeruginosa, can be introduced during the clinical procedures ${ }^{26}$, increasing the risk of failure of treatment. The maintenance of highly resistant microorganisms in the root canal such as Enterococcus faecalis is related to persistent periapical infections ${ }^{24}$.

Therefore, the success of the endodontic therapy is mainly dependent on the susceptibility of the infecting organism to the commonly used antimicrobial agents.

Chlorhexidine is an agent used in periodontology for more than 20 years, due to its antimicrobial properties and low cytotoxicity ${ }^{5,13,14}$. It can be used as an endodontic irrigant $\mathrm{t}^{2,4,19,28}$ and as an intracanal medication ${ }^{1,3,6,10,11,17,21,22,23}$.

Paramonochlorophenol (PMC) is a phenol-derived agent that exhibits broad antiseptic activity but also high toxicity. In order to reduce its cytotoxic effect while maintaining or even increasing its antimicrobial activity, combinations of PMC with other agents and vehicles and different application methods have been proposed ${ }^{3,7,12,16,22,25}$.

Based on the need to use antimicrobial agents during the endodontic therapy, the aim of this study was to determine the minimum inhibitory concentrations (MICs) of chlorhexidine digluconate and PMC for Pseudomonas aeruginosa, Staphylococcus aureus, Enterococcus faecalis, Escherichia coli, Candida albicans, Prevotella intermedia, Porphyromonas gingivalis, Porphyromonas endodontalis, Prevotella denticola and Prevotella melaninogenica.

\section{MATERIAL AND METHODS}

The strains Porphyromonas gingivalis - ATCC 33277, Porphyromonas endodontalis - ATCC 35406, Prevotella intermedia - ATCC 33563, Prevotella denticola - ATCC 35308, Prevotella melaninogenica - ATCC 33563 were obtained from the American Type Culture Collection (Rockville, MD, USA). Clinical isolates of Pseudomonas aeruginosa, Enterococcus faecalis, Staphylococcus aureus, Escherichia coli and Candida albicans belonging to the culture collection of the Oral Microbiology Laboratory, Biomedical Sciences Institute, University of São Paulo (SP, Brazil) were also used.

All microorganisms were maintained in frozen stocks in skim milk (Difco, Detroit, Michigan, USA) in a freezer at $-80^{\circ} \mathrm{C}$. Aliquots of Pseudomonas aeruginosa, Staphylococcus aureus, Enterococcus faecalis, and Escherichia coli were inoculated in brain-heart infusion agar (Biobrás Diagnósticos, Belo Horizonte, MG, Brazil) and grown overnight at $37^{\circ} \mathrm{C}$; Prevotella intermedia, Porphyromonas gingivalis, Porphyromonas endodontalis, Prevotella denticola and Prevotella melaninogenica were cultured in brucella agar (Oxoid, Basingstoke, Hampshire, England) supplemented with 5\% defibrinated sheep blood, $5 \mu \mathrm{g} / \mathrm{ml}$ of hemin (Sigma Chemical Co., St. Louis, USA) and $1 \mu \mathrm{g} / \mathrm{ml}$ of menadione (Sigma) in anaerobic jars (Oxoid) for 6 days at $37^{\circ} \mathrm{C}$. Candida albicans was cultured in Sabouraud agar tubes (Biobrás) at room temperature, for 4 days.

Minimum inhibitory concentrations (MICs) were determined by the agar dilution method. The growth resulting from the plates with Pseudomonas aeruginosa, Staphylococcus aureus, Enterococcus faecalis, Escherichia coli and Candida albicans was scraped with a platinum loop, and diluted in phosphate buffered saline solution (Sigma), pH 7.4 to an absorbance of 0.5 at $560 \mathrm{~nm}\left(\AA_{560}=0.5\right)$.

The colonies of Prevotella intermedia, Prevotella denticola, Prevotella melaninogenica, Porphyromonas gingivalis and Porphyromonas endodontalis were scraped from the plates, and resuspended in Ringer-PRAS solution, $\mathrm{pH} 7.2$ to an absorbance of 2.0 at $560 \mathrm{~nm}\left(\AA_{560}=2.0\right)$.

Stock solutions of $20 \%$ chlorhexidine digluconate and 98\% paramonochlorophenol (Oficinalis, São Paulo, SP, Brazil) were used. Samples of the bacterial suspensions were deposited on the surface of agar plates by means of a Steers replicating device (Cefar Diagnóstica, São Paulo, SP, Brazil). Mueller-Hinton (Biobrás) agar plates containing different concentrations of chlorhexidine digluconate $(1.67 \mu \mathrm{g} / \mathrm{ml}$ to $200 \mu \mathrm{g} / \mathrm{ml})$ or paramonochlorophenol $(6.67 \mu \mathrm{g} / \mathrm{ml}$ to $244 \mu \mathrm{g} / \mathrm{ml})$ were inoculated with Pseudomonas aeruginosa, Staphylococcus aureus, Enterococcus faecalis and Escherichia coli, and incubated at $37^{\circ} \mathrm{C}$ for 24 hours. Brucella agar plates supplemented with $5 \mu \mathrm{g} / \mathrm{ml}$ of hemin and $1 \mu \mathrm{g} / \mathrm{ml}$ of menadione added with different concentrations of chlorhexidine $(1.21 \mu \mathrm{g} / \mathrm{ml}$ to $72.81 \mu \mathrm{g} / \mathrm{ml})$ or paramonochlorophenol $(4.85 \mu \mathrm{g} / \mathrm{ml}$ to $485.44 \mu \mathrm{g} /$ ml) were inoculated with Prevotella intermedia, Prevotella denticola, Prevotella melaninogenica, Porphyromonas gingivalis or Porphyromonas endodontalis and incubated at $37^{\circ} \mathrm{C}$ in anaerobic jars using gas generating kits (Oxoid) for 6 days.

Sabouraud agar plates with different concentrations of each antimicrobial agent were inoculated by spotting $10 \mu \mathrm{l}$ of the Candida albicans 
Amorim CVG, Aun CE, Mayer MPA. Susceptibility of some oral microorganisms to chlorhexidine and paramonochlorophenol. Braz Oral Res 2004;18(3):242-6.

suspension using a micropipette, and incubated at room temperature, for 6 days.

Plates containing no antimicrobial agents were used as positive control. All the tests were performed in six plates and the MIC was defined as the lowest concentration of chlorhexidine or paramonochlorophenol that prevented visible bacterial growth.

\section{RESULTS}

Chlorhexidine MIC values varied from 2.67 to $80.00 \mu \mathrm{g} / \mathrm{ml}$ and PMC MIC varied from 46.67 to $213.33 \mu \mathrm{g} / \mathrm{ml}$. The MICs of chlorhexidine and PMC for the tested microorganisms are expressed in Table 1. The highest MIC value of paramonochlorophenol observed was for Enterococcus faecalis and the highest MIC value of chlorhexidine digluconate observed was for Pseudomonas aeruginosa.

\section{DISCUSSION}

The antimicrobial effects of agents used as intracanal medications or irrigants on oral microorganisms have been extensively investigated. However, the effect of PMC on most organisms, mainly strict anaerobes, is still not elucidated, despite its extensive use in endodontic therapy. In addition, most studies on chlorhexidine discuss its effect on periodontopathogenic microorganisms only. The effectiveness of an antimicrobial agent depends, among other factors, on the susceptibility of the involved species to this agent, justifying the use of an intracanal medication of broad spectrum

TABLE 1 - Minimum inhibitory concentrations $(\mu \mathrm{g} / \mathrm{ml})$ of chlorhexidine and paramonochlorophenol (PMC) for the tested microorganisms.

\begin{tabular}{l|c|r}
\hline \hline & $\begin{array}{c}\text { Chlor- } \\
\text { hexidine }\end{array}$ & PMC \\
\hline Pseudomonas aeruginosa & 80.00 & 126.67 \\
\hline Staphylococcus aureus & 4.00 & 126.67 \\
\hline Candida albicans & 4.00 & 46.67 \\
\hline Porphyromonas gingivalis & 3.40 & 194.17 \\
\hline Porphyromonas endodontalis & 3.40 & 194.17 \\
\hline Prevotella melaninogenica & 3.40 & 194.17 \\
\hline Prevotella intermedia & 3.40 & 194.17 \\
\hline Enterococcus faecalis & 3.33 & 213.33 \\
\hline Escherichia coli & 2.67 & 93.33 \\
\hline Prevotella denticola & 2.67 & 174.76 \\
\hline \hline
\end{tabular}

to complement the disinfection of the root canal ${ }^{8}$. In order to determine the susceptibility of the studied microorganisms to the antimicrobial agents studied, the dilution test in agar was chosen. This procedure presents several advantages over the diffusion tests usually employed, such as allowing the use of volatile agents as PMC, and providing MIC results. In addition, the dilution test in agar is not dependent on the diffusion of the agent in the culture medium, and is the method of choice for testing antimicrobials against anaerobic bacteria $^{18}$. Blood was added to the culture medium in order to enable the appropriate growth of strict anaerobes. It is known that the presence of blood in the composition of the culture medium may alter the $\mathrm{MIC}^{14}$. Nevertheless, the data obtained suggest that both agents were effective against anaerobic bacteria even at high concentrations of blood. The susceptibility of the microorganism to the antimicrobial drugs varied according to the agent. Pseudomonas aeruginosa, Staphylococcus aureus and the strict anaerobes presented intermediate susceptibility to paramonochlorophenol, whereas Escherichia coli was the most susceptible microorganism to this agent. Enterococcus faecalis exhibited the highest MIC value for PMC, approximately 4.6 times higher than the value for Candida albicans, which presented the lowest MIC. The average value of paramonochlorophenol MIC for the strict anaerobes (except Prevotella denticola) was approximately 1.4 times higher than that for Escherichia coli.

Pseudomonas aeruginosa was also the least susceptible organism to chlorhexidine. The increased resistance of Pseudomonas aeruginosa to chlorhexidine was also reported by other authors ${ }^{5,13}$ and is also in agreement with studies showing the emergence of $P$. aeruginosa in nosocomial infections. The MIC value of chlorhexidine for $P$. aeruginosa was approximately 30 times higher than the values observed for Prevotella denticola and Escherichia coli, which presented the lowest MIC values. Staphylococcus aureus, Pseudomonas aeruginosa, and Candida albicans presented higher MIC values of chlorhexidine than Gramnegative strict anaerobes, such as Prevotella intermedia, Porphyromonas gingivalis, Porphyromonas endodontalis, Prevotella denticola and Prevotella melaninogenica. Pseudomonas aeruginosa is not a resident microorganism of the oral cavity, and its growth in the root canal should be prevented with the adoption of proper biosafety procedures. Due to the persistence of Enterococcus faecalis 
Amorim CVG, Aun CE, Mayer MPA. Susceptibility of some oral microorganisms to chlorhexidine and paramonochlorophenol. Braz Oral Res 2004;18(3):242-6.

and yeast in periapical lesions, and to the role of anaerobic organisms in endodontic infections with clinical symptoms, the MIC data reported in this study suggest that chlorhexidine be chosen as an antimicrobial agent for endodontic therapies. However, Roach et al. ${ }^{22}$ (2001) reported the resistance of Enterococcus faecalis to chlorhexidine/methylcellulose gel penetration of a root canal model, when compared with calcium hydroxide/methylcellulose paste, camphorated parachlorophenol/ calcium hydroxide paste.

Almyroudi et al. ${ }^{1}$ (2002) demonstrated that all tested chlorhexidine formulations were effective in eliminating Enterococcus faecalis from dentinal tubules, with $1 \%$ chlorhexidine gel exhibiting slightly better results. Gomes et al. ${ }^{11}$ (2003b) observed that $2 \%$ chlorhexidine gel alone was more effective against Enterococcus faecalis than calcium hydroxide. Evans et al. ${ }^{6}$ (2003) demonstrated that the calcium hydroxide paste with $2 \%$ chlorhexidine was more effective in killing Enterococcus faecalis in dentinal tubules than calcium hydroxide diluted in water.

In addition, Podbielski et al. ${ }^{21}$ (2003) reported that calcium hydroxide did not adversely affect the solubility and activity of chlorhexidine but rather exhibited an additive effect on some Gram-positive endodontic pathogens like Peptostreptococcus micros and Streptococcus intermedius. Even though the combination between calcium hydroxide, zinc oxide and chlorhexidine led to a faster decrease in the overall number of viable $E$. faecalis cells, no test conditions led to the complete loss of culture viability.

In the present study, the MIC of chlorhexidine for $C$. albicans was $4 \mu \mathrm{g} / \mathrm{ml}$ higher than that reported by Ferguson et al. ${ }^{7}$ (2002). The discrepancies in antimicrobial sensitivity tests are due to variations in methodology, since a large number of factors (inoculum amount, medium composition, $\mathrm{pH}$, incubation) can influence the interaction between microorganisms and antimicrobial agents, thus affecting the value obtained for MIC.

Besides its low cytotoxicity and high anti-

\section{REFERENCES}

1. Almyroudi A, Mackenzie D, McHugh S, Saunders WP. The effectiveness of various disinfectants used as endodontic intracanal medications: an in vitro study. J Endod 2002;28(3):163-7.

2. Ayhan H, Sultan N, Çirak M, Ruhi MZ, Bodur H. Antimicrobial effects of various endodontic irrigants on selected microorganisms. Int Endod J 1999;32:99-102. microbial activity, chlorhexidine presents other properties that indicate its use in endodontic treatments. Chlorhexidine is able to interact with oral tissues ${ }^{14,20}$ and to continue to be released for a longer period of time. Another advantage of chlorhexidine is its property of maintaining the disinfecting activity after contact with organic matter, unlike sodium hypochlorite ${ }^{8}$, another irrigant agent commonly used in endodontic treatments. These characteristics lead to an increased resistance of dentine treated with chlorhexidine solutions against reinfections ${ }^{15}$. In addition, Lenet et al. ${ }^{17}$ (2000) reported that bovine root canal models medicated with $2 \%$ chlorhexidine gel for 7 days acquire antimicrobial properties against Enterococcus faecalis for at least 21 days.

On the other hand, the results of this in vitro study showed that both chlorhexidine and paramonochlorophenol were effective in inhibiting the development of all tested microorganisms at concentrations much lower than those used in endodontic therapies. The low MIC values for chlorhexidine and PMC justify the low concentrations proposed for their use as filling materials ${ }^{3,23}$. Mainly in the case of PMC, the low concentration used when filling the dental canal minimizes its cytotoxic action, while keeping its antimicrobial activity ${ }^{3,17}$.

The present data suggest that chlorhexidine digluconate can be used as an antimicrobial agent in clinical situations with persistence of signs and symptoms after the conventional endodontic procedures. Chlorhexidine should be used as the choice or alternative intracanal medication, due to its safety and antimicrobial properties.

\section{CONCLUSIONS}

These data showed that paramonochlorophenol and chlorhexidine digluconate present antimicrobial activity against several microorganisms commonly found in endodontic infections, even at low concentrations, suggesting their effectiveness when used as intracanal medication.

3. Barbosa CA, Gonçalves RB, Siqueira Junior JF, Uzeda M Evaluation of the antibacterial activities of calcium hydroxide, chlorhexidine, and camphorated paramonochlorophenol as intracanal medicament. A clinical and laboratory study. J Endod 1997;23:297-300.

4. Delany GM, Patterson SS, Miller CH, Newton CW. The effect of chlorhexidine gluconate irrigation on the root canal flora 
Amorim CVG, Aun CE, Mayer MPA. Susceptibility of some oral microorganisms to chlorhexidine and paramonochlorophenol. Braz Oral Res 2004;18(3):242-6.

of freshly extracted necrotic teeth. Oral Surg Oral Med Oral Pathol 1982;53:518-23.

5. Emilson CG. Susceptibility of various microorganisms to chlorhexidine. Scand J Dent Res 1977;85:255-65.

6. Evans MD, Baumgartner JC, Khemaleelakul S, Xia T. Efficacy of calcium hydroxide: chlorhexidine paste as an intracanal medication in bovine dentin. J Endod 2003;29(5):3389.

7. Ferguson JW, Hatton JF, Gillespie MJ. Effectiveness of intracanal irrigants and medications against the yeast Candida albicans. J Endod 2002;28(2):68-71.

8. Gélinas P, Goulet J. Neutralization of the activity of eight disinfectants by organic matter. J Appl Bacteriol 1983;54:243-7.

9. Gomes BPFA, Lilley JD, Drucker DB. Association of endodontic symptoms and signs with particular combinations of specific bacteria. Int Endod J 1996;29:69-75.

10. Gomes BPFA, Sato E, Ferraz CCR, Teixeira FB, Zaia AA, Souza-Filho FJ. Evaluation of time required for recontamination of coronally sealed canals medicated with calcium hydroxide and chlorhexidine. Int Endod $\mathrm{J}$ 2003a;36:604-9.

11. Gomes BPFA, Souza SFC, Ferraz CCR, Teixeira FB, Zaia AA, Valdrighi L, Souza-Filho FJ. Effectiveness of $2 \%$ chlorhexidine gel and calcium hydroxide against Enterococcus faecalis in bovine root dentine in vitro. Int Endod $\mathrm{J}$ 2003b;36:267-75.

12. Harrison JW, Madonia JV. Antimicrobial effectiveness of parachlorophenol. Oral Surg Oral Med Oral Pathol 1970;30:267-75.

13. Hennessey TD. Some antibacterial properties of chlorhexidine. J Periodontal Res 1973;8:61-7.

14. Hjeljord LG, Rolla G, Bonesvoll P. Chlorhexidine-protein interactions. J Periodontal Res 1973;8:11-6.

15. Jung S, Safavi K, Spangberg L. The effectiveness of chlorhexidine in the prevention of root canal reinfection. J Endod 1999;25:288 (OR26).

16. Kawahara CM, Regan PF, Tenca JI, Pelleu GB Jr. Antimicrobial efficacy of reduced concentrations of parachlorophenol in extracted teeth. J Endod 1975;1:4852 .
17. Lenet BJ, Komorowski R, Wu XY, Huang J, Grad H, Lawrence HP, et al. Antimicrobial substantivity of bovine root dentin exposed to different chlorhexidine delivery vehicles. J Endod 2000;26(11)652-5.

18. Lorian V. Antibiotics in laboratory medicine. $3^{\text {rd }}$ ed. Baltimore: Williams \& Wilkins; 1991

19. Öztan MD. Endodontic treatment of teeth associated with a large periapical lesion. Int Endod J 2002;35:73-8.

20. Parsons GJ, Patterson SS, Miller CH, Katz S, Kafrawy AH, Newton CW. Uptake and release of chlorhexidine by bovine pulp and dentin specimens and their subsequent acquisition of antibacterial properties. Oral Surg Oral Med Oral Pathol 1980;49:455-9.

21. Podbielski A, Spahr A, Haller B. Additive antimicrobial activity of calcium hydroxide and chlorhexidine on common endodontic bacterial pathogens. J Endod 2003;29(5):3405 .

22. Roach RP, Hatton JF, Gillespie MJ. Prevention of the ingress of a known virulent bacterium into root canal system by intracanal medications. J Endod 2001;27(11): 657-60.

23. Siqueira $\mathrm{Jr} \mathrm{JF}$, Uzeda M. Intracanal medicaments: evaluation of the antibacterial effects of chlorhexidine, metronidazole, and calcium hydroxide associated with three vehicles. J Endod 1997;23:167-9.

24. Siren EK, Haapasalo M, Ranta K, Salmi P, Kerosuo ENJ. Microbiological findings and clinical treatment procedures in endodontic cases selected for microbiological investigation. Int Endod J 1997;30:91-5.

25. Soekanto A, Kasugai S, Mataki S, Ohya K, Ogura H. Toxicity of camphorated phenol and camphorated parachlorophenol in dental pulp cell culture. J Endod 1996;22:2849.

26. Sundqvist G. Taxonomy, ecology, and pathogenicity of the root canal flora. Oral Surg Oral Med Oral Pathol 1994;78:522-30.

27. Sundqvist G, Johansson E, Sjögren U. Prevalence of black-pigmented bacteroides species in root canal infections. J Endod 1989;15:13-9.

28. White RR, Hays GL, Janer LR. Residual antimicrobial activity after canal irrigation with chlorhexidine. J Endod 1997;23:229-31.
Received for publication on Sep 23, 2003

Sent for alterations on Mar 08, 2004

Accepted for publication on May 26, 2004 